Article

\title{
Complex Study of Eutectoidal Phase Transformation of 2507-Type Super-Duplex Stainless Steel
}

\author{
István Mészáros and Bálint Bögre * \\ Department of Materials Science and Engineering, Budapest University of Technology and Economics, \\ Bertalan Lajos utca 7, 1111 Budapest, Hungary \\ * Correspondence: bbalint1113@gmail.com; Tel.: +36-30-590-9566
}

Received: 3 June 2019; Accepted: 4 July 2019; Published: 9 July 2019

\begin{abstract}
The aim of this work was to study expansively the process of the eutectoidal phase transformation of 2507-type super-duplex stainless steel. Three sample sets were prepared. The first sample set was made to investigate the effect of the previous cold rolling and heat treatment for the eutectoidal phase transformation. Samples were cold rolled at seven different rolling reductions which was followed by heat treatment at five different temperatures. The second sample set was prepared to determine the activation energy of the eutectoidal decomposition process using the Arrhenius equation. Samples were cold rolled at seven different rolling reductions and were heat treated at the same temperature during eight different terms. A third sample set was made to study how another plastic-forming technology, beside the cold rolling, can influence the eutectoidal decomposition. Samples were elongated by single axis tensile stress and were heat treated at the same temperature. The results of the first and the third sample sets were compared. The rest $\delta$-ferrite contents were calculated using the results of AC and DC magnetometer measurements. DC magnetometer was used as a feritscope device in this work. Light microscope and electron back scattering diffraction (EBSD) images demonstrated the process of the eutectoidal decomposition. The thermoelectric power and the hardness of the samples were measured. The results of the thermoelectric power measurement were compared with the results of the $\delta$-ferrite content measurement. The accurate value of the coercive field was determined by a Foerster-type DC coercimeter device.
\end{abstract}

Keywords: duplex stainless steel; eutectoidal decomposition; cold rolling; heat treatment; magnetic testing; thermoelectric power; EBSD; activation energy

\section{Introduction}

Duplex stainless steel (DSS) has a double-phase microstructure containing, in approximate equal proportion, ferrite and austenite. The double-phase structure causes an excellent combination of strength and corrosion resistance, mainly in chloric medium. DSS is used mainly in chemical processing and transport, oil and gas refining, paper manufacturing, and in the marine environment [1-3].

Table 1 shows the characteristic chemical composition of DSS, which provides the favorable properties of this type stainless steel [3].

Table 1. Chemical composition of duplex stainless steel (DSS) (\%) [3].

\begin{tabular}{ccccccc}
\hline C Max. & Cr & Ni & Mo & W & Cu & N \\
\hline 0.03 & $22-25$ & $4-7$ & $0-4$ & $0-2$ & $0-1.5$ & $0.1-0.35$ \\
\hline
\end{tabular}


The carbon content of DSS is strictly limited because of corrosion resistance. The high chromium alloying increases the corrosion resistance until the nickel improves the toughness. The nitrogen increases the strength and resistance against the pitting corrosion.

In the double-phase structure, the austenite-forming elements $(\mathrm{C}, \mathrm{Ni}, \mathrm{N}, \mathrm{Cu})$ and ferrite-forming elements $(\mathrm{Cr}, \mathrm{Mo}, \mathrm{W})$ have a well-adjusted ratio, which is the base of the microstructural equilibrium. The austenite ensures the good ductility, toughness, and weldability until the ferrite raises the corrosion resistance mainly against the pitting, stress, and crevice corrosion.

Secondary phases can appear during the heat treatment in the critical temperature range, about $300-1000{ }^{\circ} \mathrm{C}$, due to the metastable structure. Higher alloying content (mainly the chromium and molybdenum) can increase the chance of the forming of precipitations. The appearance of these phases are dangerous because these can cause the dramatic decrease of the ductility and the corrosion resistance. Figure 1 shows these typical precipitations of DSS. Among them, the tetragonal $\sigma$-phase is the most significant, which can appear in the case of molybdenum alloying in the temperature range 600-1000 ${ }^{\circ} \mathrm{C}$. $x$-phase $\left(\mathrm{Fe}_{36} \mathrm{Cr}_{12} \mathrm{Mo}_{10}\right)$ can form between $700-850{ }^{\circ} \mathrm{C}$. $\mathrm{The} \mathrm{Cr}_{2} \mathrm{~N}$ precipitation has a hexagonal crystal lattice and settles down at the border of the ferrite grains. The high chromium content of $\mathrm{Cr}_{2} \mathrm{~N}$ causes chromium impoverishment in its environment which can cause intensified corrosion sensibility. The R-phase forms in the temperature range $550-650{ }^{\circ} \mathrm{C}$ and it increases the brittleness. $\mathrm{M}_{23} \mathrm{C}_{6}$ and $\mathrm{M}_{7} \mathrm{C}_{3}$ precipitations are complex carbides with high chromium content. The above characterized precipitations appear at high temperature and in a relatively short time, as it can be seen in Figure 1 [1-7].

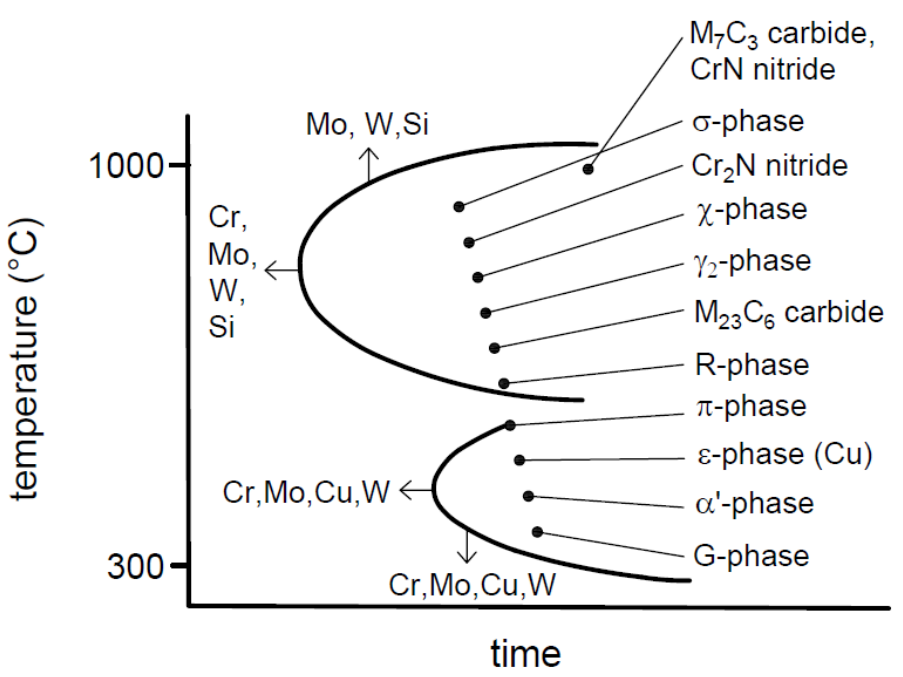

Figure 1. Typical precipitations of duplex stainless steel.

The temperature range of the brittle $\pi$-phase $\left(\mathrm{Fe}_{7} \mathrm{Mo}_{13} \mathrm{~N}_{4}\right)$ is at $550-600{ }^{\circ} \mathrm{C}$. $\varepsilon$-phase $\left(\mathrm{Fe}_{3} \mathrm{~N}\right.$ and $\mathrm{Fe}_{2} \mathrm{~N}$ ) which is a nitride similarly to the $\pi$-phase can be noticed in copper-alloyed DSS. $\alpha^{\prime}$-phase has the most notable effect at low temperature. This precipitation causes the $475^{\circ} \mathrm{C}$ embrittlement and ferritic zones which are rich in chromium.

The most significant phase transformation in duplex stainless steel is the eutectoidal decomposition of $\delta$-ferrite while $\delta$-ferrite transforms into $\sigma$-phase and secondary austenite $\left(\delta \rightarrow \sigma+\gamma_{2}\right)[1-7]$.

Figure 2 represents G. Herbstleb and P. Schwaab's simplified precipitation diagram for DSS [3]. $\mathrm{M}_{23} \mathrm{C}_{6}$-type complex carbides with high chromium content form at the border of the $\delta$-ferrite grains $(\delta / \delta)$ at the early stage of the decomposition of $\delta$-ferrite. The appearance of the $\mathrm{M}_{23} \mathrm{C}_{6}$-type carbides passes any other phase transformation due to the high mobility of the carbon, as Figure 2 illustrates. The carbon atoms diffuse to the grain boundary because the enrichment of the carbide-forming alloys (mainly chromium and molybdenum) are significant at the boundary. These carbides can be favorable places for the later-forming $\sigma$-phase and secondary austenite. 


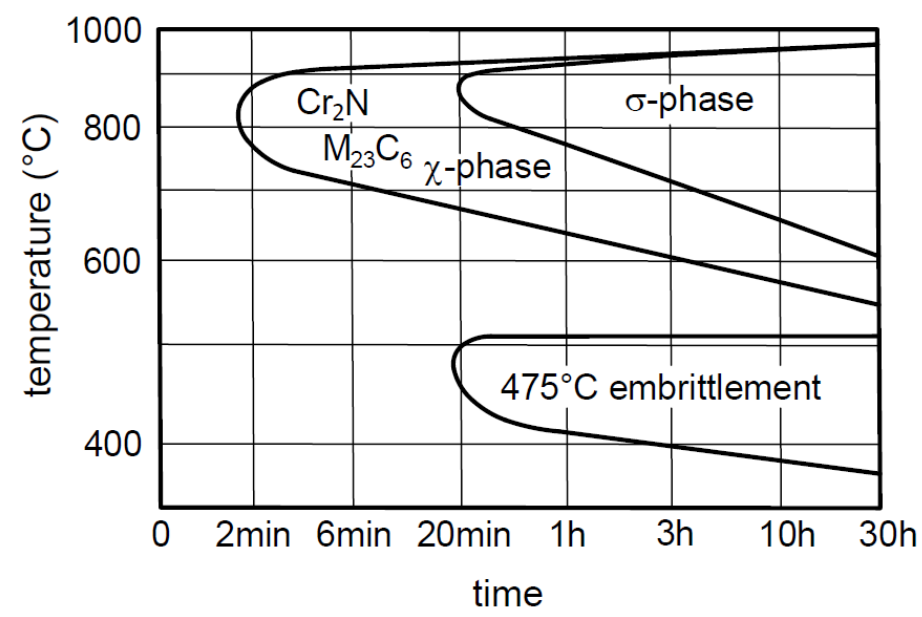

Figure 2. G. Herbstleb and P. Schwaab's simplified precipitation diagram for duplex stainless steel.

Figure 3 illustrates the kinetics of the eutectoidal decomposition of $\delta$-ferrite [1-7]. The distribution of the alloying elements is not homogeneous in DSS due to its dual phase structure. The $\delta$-ferrite is richer in ferrite- and carbide-forming elements (chromium and the molybdenum) and poorer in austenite-forming elements (nickel and nitrogen). The distribution of the above-mentioned alloying elements is opposite in austenite. Due to heat treatment the chromium and molybdenum diffuse to the grain boundary of the $\delta$-ferrite/austenite and form $\sigma$-phase precipitations. Meanwhile the $\delta$-ferrite becomes poor in these alloying elements, loses its stability, and transforms into secondary austenite [8].

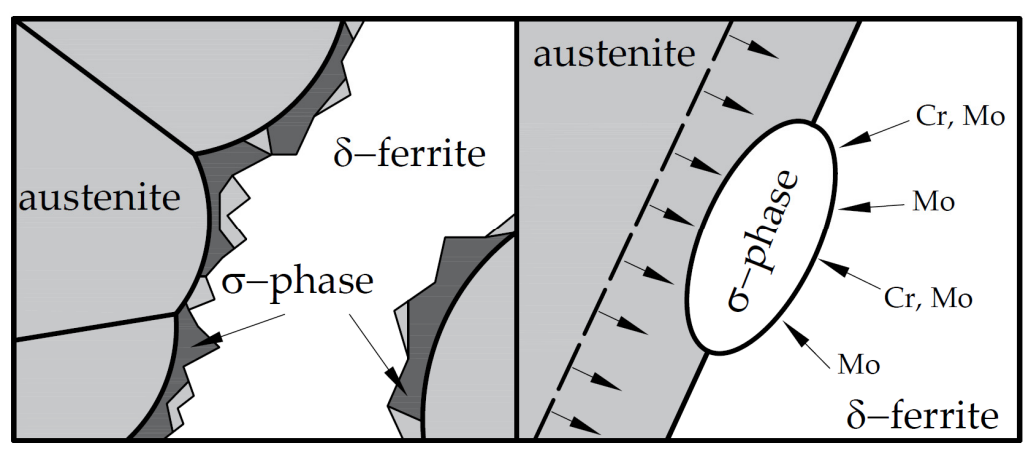

Figure 3. Kinetics of the eutectoidal decomposition of $\delta$-ferrite in DSS.

The above-presented description showed how complex metallurgical processes can take place in DSS. The application temperature of DSS is limited at maximum $280-325^{\circ} \mathrm{C}$ due to the appearance of the undesirable precipitations [3,9-18].

DSS has four grades with different pitting resistance equivalent numbers (PREN) which can characterize the corrosion resistance of the steel: lean DSS (PREN < 35), standard DSS (PREN 35-40), super-duplex stainless steel (SDSS) (PREN 40-45), and hyper-DSS (PREN > 45) [3,9-18].

The aim of this paper is to study, complexly, how the previous cold rolling can influence the eutectoidal decomposition of $\delta$-ferrite in 2507 SDSS during the heat treatment.

\section{Material and Sample Preparation}

Tables 2 and 3 show the nominal chemical composition and the main mechanical properties of the 2507-type SDSS. The main alloying elements are the chromium (about 25\%) and the nickel (about 7\%). 
Table 2. Chemical composition of the 2507-type SDSS (\%).

\begin{tabular}{cccccccccccc}
\hline $\mathbf{C}$ & $\mathbf{M n}$ & $\mathbf{P}$ & $\mathbf{S}$ & $\mathbf{S i}$ & $\mathbf{C u}$ & $\mathbf{N i}$ & $\mathbf{C r}$ & $\mathbf{M o}$ & $\mathbf{N b}$ & $\mathbf{T i}$ & $\mathbf{N}$ \\
\hline 0.021 & 0.822 & 0.023 & 0.0004 & 0.313 & 0.178 & 6.592 & 24.792 & 3.705 & 0.008 & 0.005 & 0.264 \\
\hline
\end{tabular}

Table 3. Mechanical properties of the 2507-type SDSS.

\begin{tabular}{ccc}
\hline Yield Stress $\mathbf{R p}_{\mathbf{0 . 2}} \mathbf{( M P a )}$ & Tensile Stress $\mathbf{R m}$ (MPa) & Elongation at Fracture A (\%) \\
\hline 634 & 829 & 26 \\
\hline
\end{tabular}

Figure 4 represents the original sheet material and the directions of the manufacturing hot rolling and the experimental cold rolling. Samples were cut from sheet material with a band saw. The thickness $\left(\mathrm{h}_{0}\right)$ was about $10 \mathrm{~mm}$, the width $\left(\mathrm{w}_{0}\right)$ was about $15 \mathrm{~mm}$, and the length $\left(\mathrm{l}_{0}\right)$ was about $100 \mathrm{~mm}$ of the cut samples.

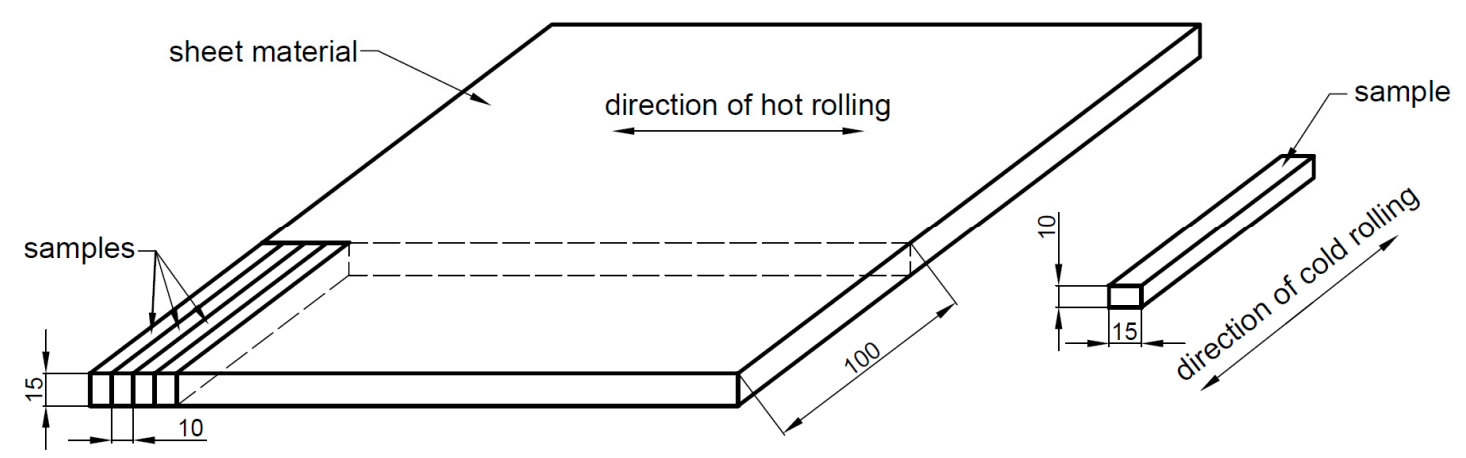

Figure 4. Directions of the manufacturing hot rolling and the experimental cold rolling.

The samples were cold rolled by a $Ø 300 \mathrm{~mm}$ diameter double-cylinder rolling machine. The direction of the cold rolling was perpendicular to the direction of the manufacturing hot rolling. The thickness reductions were $0.25 \mathrm{~mm}$ in every rolling step.

\section{Test Results and Discussion}

\subsection{First Sample Set}

The first sample set was prepared to study the process of the eutectoidal phase transformation due to the previous cold rolling and heat treatment. The seven rolling reductions $(\varepsilon)$ were the following: $0 \%, 10.3 \%, 22.3 \%, 31.3 \%, 41.6 \%, 50.6 \%$, and $61.9 \%$. The rolling reductions were calculated by the Equation (1):

$$
\varepsilon=\left(\mathrm{h}_{0}-\mathrm{h}\right) / \mathrm{h}_{0} * 100(\%)
$$

where " $\mathrm{h}$ " was the thickness of the rolled sample. Five samples were rolled from every rolling reduction and were heat treated at $20,700,750,800$, and $850{ }^{\circ} \mathrm{C}$ temperatures. The term of the heat treatment was $30 \mathrm{~min}$ and the samples were normalized on static normal air. Naturally, the different rolling reductions resulted in different sizes of the samples. At the end of the preparation process all samples were machined at the same size $3.4 \mathrm{~mm} \times 10 \mathrm{~mm} \times 100 \mathrm{~mm}(\mathrm{~h} \times \mathrm{w} \times \mathrm{l})$.

\subsubsection{AC Magnetometer Measurement}

In the investigated DSS, the $\delta$-ferrite is the only ferromagnetic phase which transforms to paramagnetic $\sigma$-phase and secondary austenite. Therefore, the eutectoidal decomposition influences the ferromagnetic phase ratio of the alloy. It is well known that the magnetic saturation polarization is linearly proportional to the ferromagnetic phase ratio of alloys [19]. Consequently, the $\delta$-ferrite ratio can be precisely determined from saturation polarization. 
Firstly, the samples were measured by an AC magnetometer to determine their $\delta$-ferrite content. Figure 5 illustrates the set-up of the AC magnetometer [20] which was designed and built in our laboratory. This set up is suitable only for measuring flat-stripe-shaped samples.

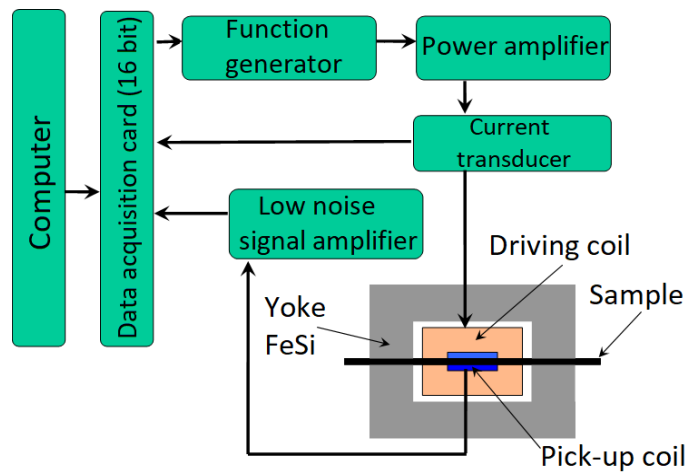

Figure 5. Set-up of the AC magnetometer.

The instrument measures the normal magnetization curve and the hysteresis loop of the samples. The maximal polarization, coercive field, remnant induction, and initial permeability can be determined from the magnetization curves.

The yoke stands from two symmetrical U-shaped laminated Fe-Si iron cores which closes the magnetic circle. The driving and the pick-up coils close round the sample. The power amplifier and the function generator supply sinusoidal excitation current which frequency is $5 \mathrm{~Hz}$. The 16-bit input-output data acquisition card accomplished the measurements. In case of each sample, 200 minor hysteresis loops were recorded. The maximum excitation field strength was about $128 \mathrm{~A} / \mathrm{cm}$ which cannot saturate the samples magnetically. Because of this physical limitation, the AC magnetometer is not able to determine the value of saturation polarization. Therefore, the $\delta$-ferrite content was calculated from the measured maximal value of polarization. The $\delta$-ferrite content of the undeformed and non-heat-treated (initial) sample was $46.9 \%$ according to the manufacturer data sheet. Its measured maximal polarization $\left(\mu_{0} M_{\max }\right)$ was $0.31 \mathrm{~T}$. The $\delta$-ferrite content of the tested samples $(x$ in $\%)$ was determined using a simple proportion with the following Equation (2):

$$
x=\frac{46.9}{0.31}\left(\mu_{0} M_{\text {max }}\right)_{\text {measured sample }}
$$

The process of the eutectoidal decomposition can be noticed particularly well in Figure 6, which represents the calculated $\delta$-ferrite contents in the function of the heat treatment temperature [21].

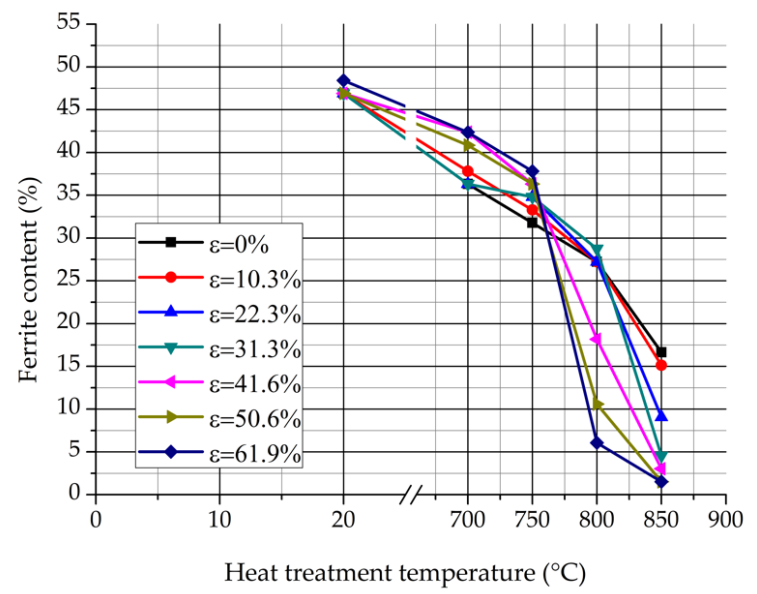

Figure 6. $\delta$-ferrite contents in function of the heat treatment temperature measured by the AC magnetometer. 
As it can be seen, the $\delta$-ferrite content of the deformed and non-heat-treated samples is about equal, the cold rolling itself cannot influence the $\delta$-ferrite content. On the other hand, it can be noticed the $\delta$-ferrite content decreases due to the heat treatment by each deformation rate because of the intensifying $\delta$-ferrite transformation. The eutectoidal decomposition starts at about $750{ }^{\circ} \mathrm{C}$ and is more intensive in deformed samples. The stronger the extent of the previous cold rolling reduction, the more the amount of the decomposed $\delta$-ferrite. In other words, the previous cold rolling promotes the $\delta$-ferrite decomposition. It is supposed that the deformation stored energy improves the number of the $\sigma$-phase nuclei during the heat treatment. Due to the growing amount of the $\sigma$-phase, more $\delta$-ferrite grains transform into secondary austenite.

\subsubsection{Magnetometer Measurement}

Secondly, the $\delta$-ferrite content of the samples was measured by a Stablein-Steinitz type DC magnetometer (designed and made in our department) and were compared with the results of the AC magnetometer. Figure 7 illustrates the set-up of the applied DC magnetometer [22,23]. The advantage of the DC magnetometer against the AC magnetometer is it can excite the samples into saturation. The highest excitation level was about $2700 \mathrm{~A} / \mathrm{cm}$, which was enough to reach the complete saturation of DSS samples. The DC magnetometer can measure the real saturation polarization until the AC magnetometer can determine just a maximal polarization value. Unfortunately, the DC magnetometer has disadvantages as well. It requires bulk samples and it can only be used in a laboratory because of its heavy size. The DC magnetometer was designed and built in our laboratory [22-24].

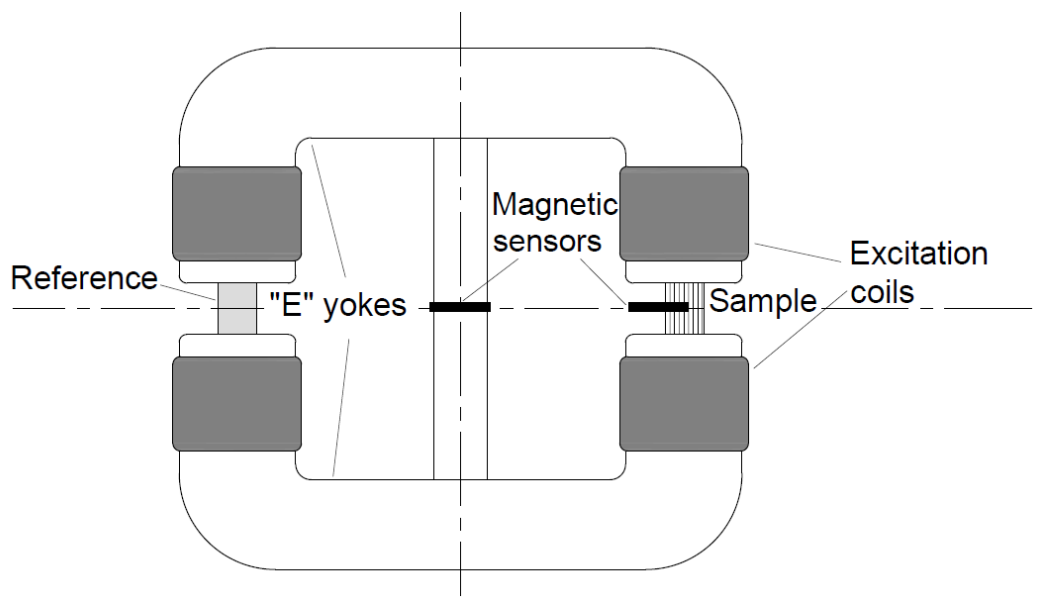

Figure 7. Set-up of the DC magnetometer.

The original version of Stablein-Steinitz type DC magnetometer was designed to record the hysteresis curve of bulk materials in the 1930s. It has symmetrical yoke which contains two U-shaped parts and a small cross-section middle bridge. The excitation is accomplished by four coils. The set-up consists of two uniform-sized air-gaps namely, the reference, and the measuring air-gaps. The arrangement is magnetically symmetrical; therefore, there is no flux in the middle bridge if the sample air-gap is empty. The symmetry of the magnetic circuit is broken by a sample taken into the sample air-gap. Therefore, some part of the flux closes through the middle bride. Our set up contained two Hall sensors and a PC-driven data acquisition unit. The sensor in the sample air-gap measures the magnetic field $(\mathrm{H})$ within the sample, the signal of the sensor in the middle bridge is directly proportional to the magnetization $(\mathrm{M})$ of the sample.

The signals of the Hall sensors are connected to the 16-bit data acquisition card through a double-channel amplifier. The excitation is supplied by a computer-controlled power amplifier. The LabView program allows for cyclical demagnetization and it can record, among others, the normal magnetization curve and the hysteresis loops of the sample [22-24]. 
The $\delta$-ferrite content was calculated from the saturation polarization values similarly to the method mentioned before. The measured saturation polarization $\left(\mu_{0} M_{\text {saturation }}\right)$ of the initial sample was $0.563 \mathrm{~T}$. The $\delta$-ferrite content of the tested samples ( $x$ in \%) was determined with the following Equation (3):

$$
x=\frac{46.9}{0.563}\left(\mu_{0} M_{\text {saturation }}\right)_{\text {measured sample }}
$$

Figure 8 represents the $\delta$-ferrite content values in function of the heat treatment temperature by the DC magnetometer measurement.

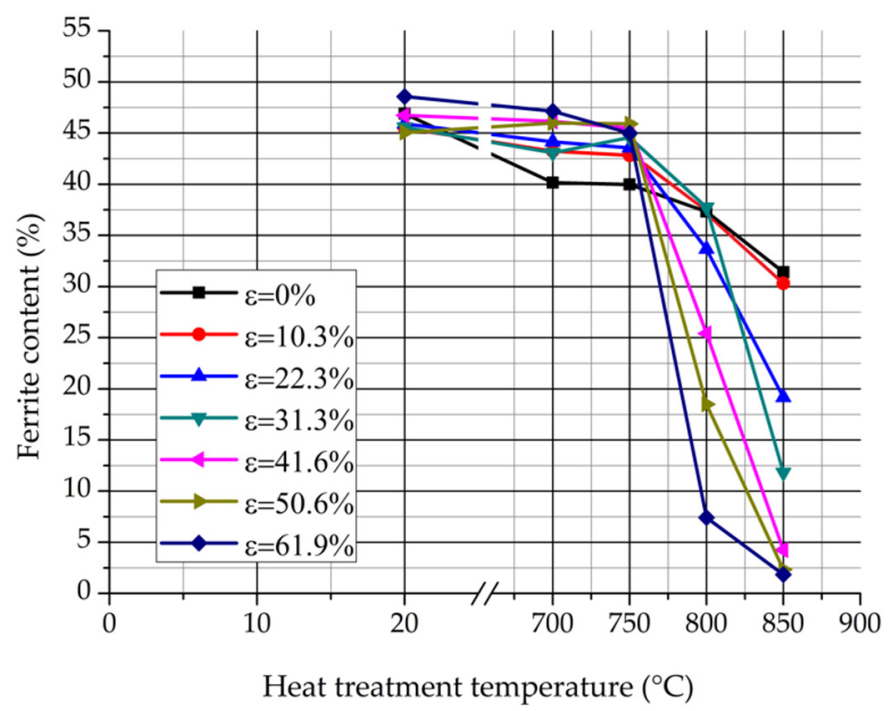

Figure 8. $\delta$-ferrite contents vs. the heat treatment temperature measured by the DC magnetometer.

The $\delta$-ferrite content reduces continuously in function of the heat treatment temperature by every rolling reduction. It can be noticed that the $\delta$-ferrite content reduction below $750{ }^{\circ} \mathrm{C}$ is less intensive than it is by the $\mathrm{AC}$ magnetometer measurement. The DC magnetometer determines higher $\delta$-ferrite contents than the AC magnetometer due to their different excitation levels. Naturally, the calculation which derives the $\delta$-ferrite contents from the real saturation polarization values give more accurate results.

In the following part of this work the DC magnetometer was used as a feritscope to determine the $\delta$-ferrite content of samples.

\subsubsection{Light Microscope}

All samples were examined by an Olympus PMG-3 type metallographic microscope (Olympus, Hamburg, Germany) which has a digital camera and the maximal magnification is $1000 \times$. During the preparation, the samples were fixed in resin and were grinded on different grain size $\mathrm{Al}_{2} \mathrm{O}_{3}$ grinding papers. After the grinding, the samples were polished on a fine cloth using $\mathrm{Al}_{2} \mathrm{O}_{3}$ suspension. Buehler EcoMet 30-type manual metallographic machine (Buehler, Lake Bluff, IL, USA) was used for the grinding and polishing. The type of etching liquid was Beraha [25].

Images were taken about all samples in the magnification of $25 \times, 50 \times, 100 \times, 500 \times$, and $1000 \times$. Figure 9 shows the microscope images of 2507-type SDSS in the magnification of 1000 $\times$. 


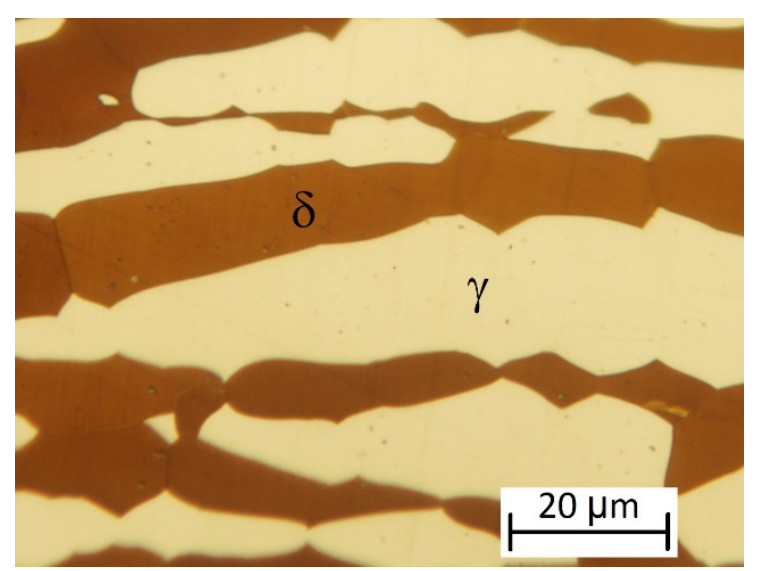

(a)

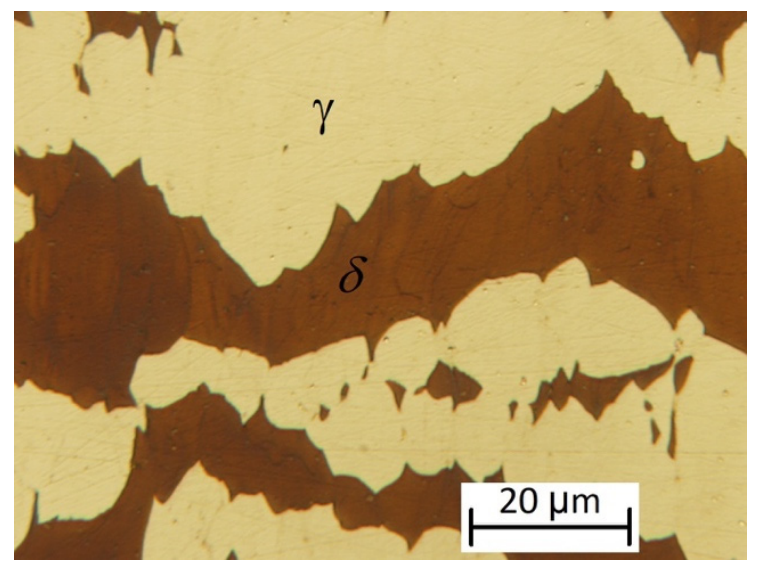

(c)

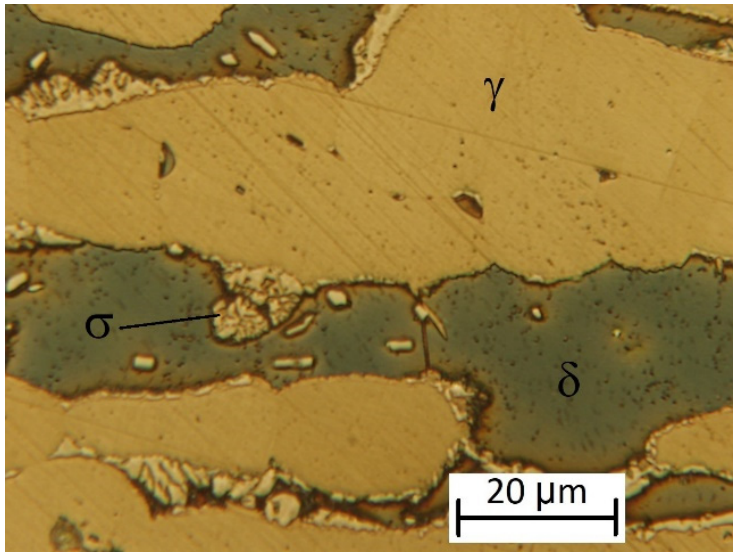

(b)

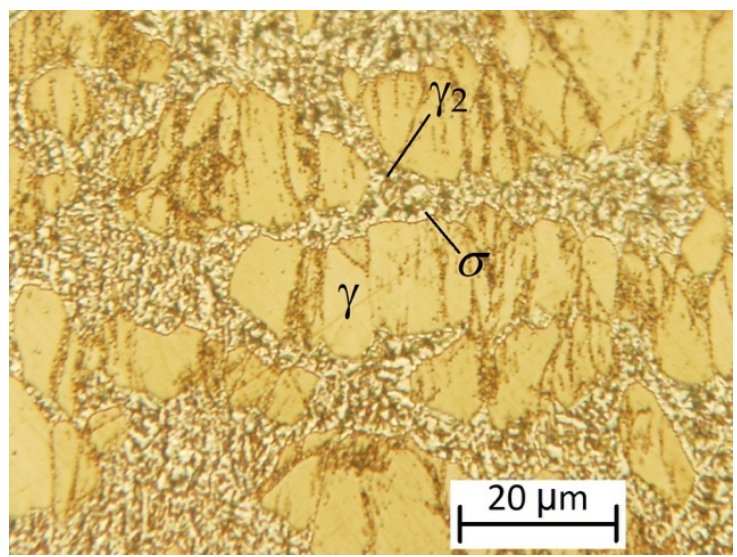

(d)

Figure 9. Microscope images of 2507-type SDSS in the magnification of 1000x: (a) Base microstructure of the 2507-type SDSS; (b) heat-treated sample at $850{ }^{\circ} \mathrm{C}$ without deformation; (c) $\varepsilon=61.9 \%$ deformed sample without heat treatment; (d) $\varepsilon=61.9 \%$ deformed sample and heat treated at $850{ }^{\circ} \mathrm{C}$.

Figure 9a shows the original microstructure of the 2507-type SDSS without deformation and heat treatment. The ratio of the $\delta$-ferrite and the austenite is almost equal. The microstructure of the heat treated sample at $850{ }^{\circ} \mathrm{C}$ without cold rolling is shown in Figure $9 \mathrm{~b}$. It can be noticed that the transformation of the $\delta$-ferrite has already begun, a slight amount of $\sigma$-phase appeared at the grain boundary of the $\delta$-ferrite and the austenite. Figure $9 \mathrm{c}$ represents the $\varepsilon=61.9 \%$ deformed samples without heat treatment. It can be seen that the decomposition of the $\delta$-ferrite cannot begin without heat treatment. Sample which was deformed in $\varepsilon=61.9 \%$ and heat treated at $850{ }^{\circ} \mathrm{C}$ is shown in Figure $9 \mathrm{~d}$. When the eutectoidal decomposition is finished, the $\delta$-ferrite transformed completely into $\sigma$-phase and secondary austenite.

\subsubsection{EBSD}

The samples were examined by a Philips XL30 ESEM FEG-type scanning electron microscope (SEM, Amsterdam, The Netherlands). The SEM has a point-source cathode of tungsten, which has a surface layer of zirconia $\left(\mathrm{ZrO}_{2}\right)$. The high tension is continuously variable from 0.2 till $30 \mathrm{kV}$ and the size of the specimen stage is $50 \mathrm{~mm} \times 50 \mathrm{~mm} \times 50 \mathrm{~mm}$.

The type and the distribution of the phases were detected by electron back scattering diffraction (EBSD). Figure 10 shows the phase maps of the 2507-type SDSS where the different phases were signed by color codes. The green color means the austenite, the red area shows the $\delta$-ferrite, and the yellow color represents the tetragonal $\sigma$-phase [26,27]. 


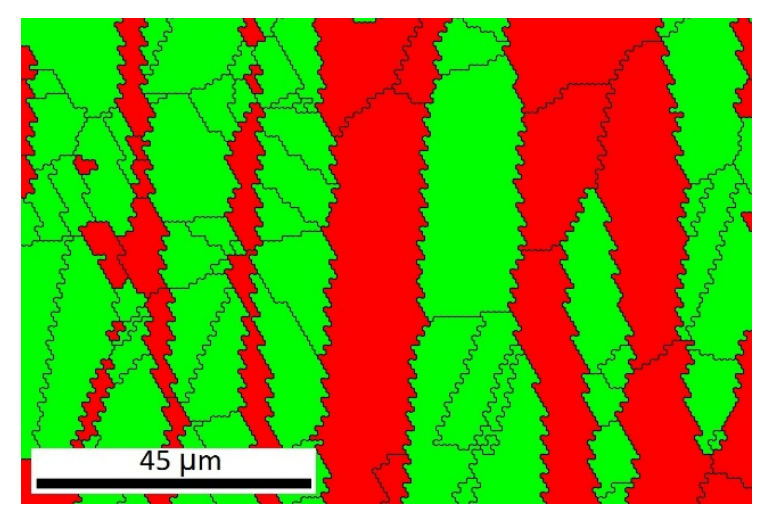

(a)

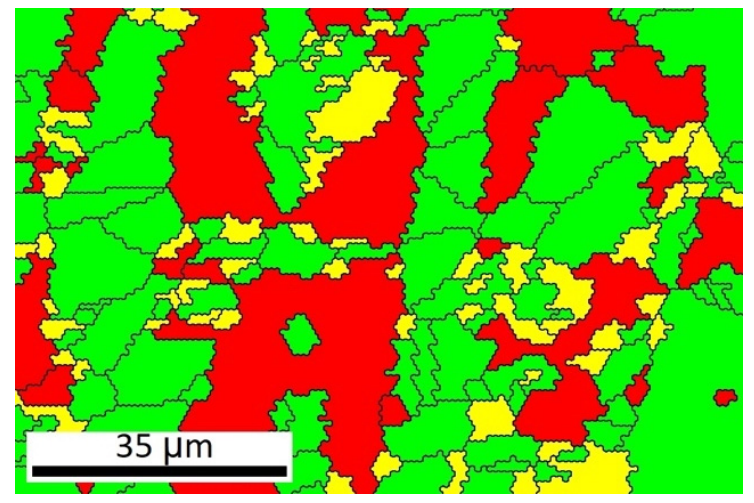

(c)

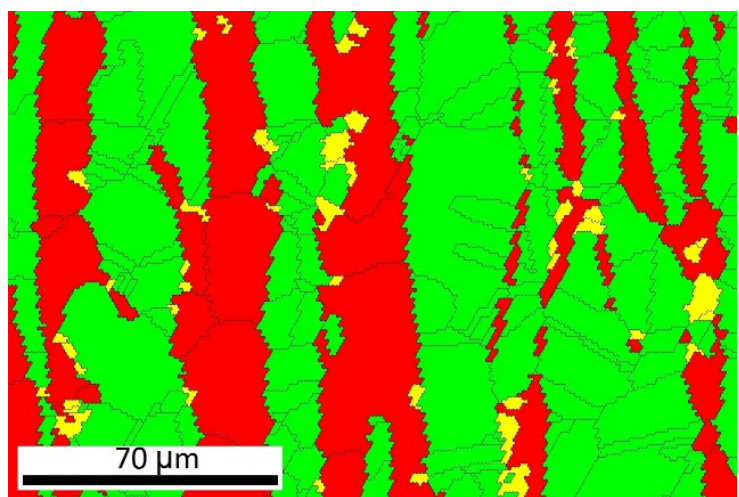

(b)

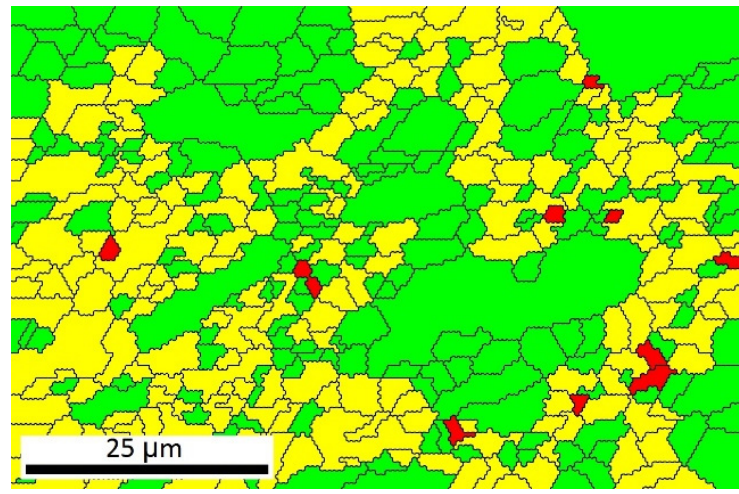

(d)

Figure 10. Phase maps made by EBSD: (a) The original phase ration of the 2507-type SDSS; (b) heat-treated sample at $850{ }^{\circ} \mathrm{C}$ without deformation; (c) $\varepsilon=22.3 \%$ deformed sample and heat treated at $850{ }^{\circ} \mathrm{C}$; (d) $\varepsilon=61.9 \%$ deformed sample and heat treated at $850{ }^{\circ} \mathrm{C}$. (Color marking: red area- $\delta$-ferrite; green area-austenite; yellow area- $\sigma$-phase).

The EBSD images can similarly illustrate the eutectoidal decomposition of $\delta$-ferrite to what was presented by the optical microscope examination. Figure 10a shows the original phase ratio: $41 \% \delta$-ferrite and $59 \%$ austenite. This result is slightly different form the value which is given on the data sheet of the 2507-type SDSS, it represents $46.9 \% \delta$-ferrite. Figure $10 \mathrm{~b}$ shows the phase map of the heat-treated sample at $850{ }^{\circ} \mathrm{C}$ without deformation. The ratio of the $\delta$-ferrite decreased from $41 \%$ to $35.3 \%$ and $3 \% \sigma$-phase appeared. The amount of the austenite increased from $59 \%$ to $61.6 \%$. The decomposition of the $\delta$-ferrite becomes more intense in Figure 10c, in which the sample is deformed in $\varepsilon=22.3 \%$ and heat treated at $850{ }^{\circ} \mathrm{C} ; 13 \% \sigma$-phase can be detected beside the $\delta$-ferrite and the austenite. The sample in Figure 10d was prepared with the maximal deformation extent and heat treatment temperature. The phase transformation of the $\delta$-ferrite has almost finished: The amount of the $\sigma$-phase increased significantly until the $\delta$-ferrite content is just about $1 \%$.

\subsubsection{Thermoelectric Power Measurement}

Thermoelectric power (TEP) was measured by a TechLab Trivolt PK120-type TEP measuring instrument (TechLab, La Tannerie, France) in order to examine if there is correlation between the eutectoidal decomposition of $\delta$-ferrite and the TEP. The TEP instrument is operated by $220 \mathrm{~V}$ and its measuring accuracy is about $2 \mathrm{nV} / \mathrm{K}$.

The basis of the TEP measurment is the Seebeck-effect. If temperature difference forms between two diverse electrical conductors or semi-conductors, voltage difference appears between the two substances. The value of the TEP is sensitive to the different material properties, especially to the chemical composition [28-30]. Figure 11 shows the sematic illustration of the TEP instrument [29]. 


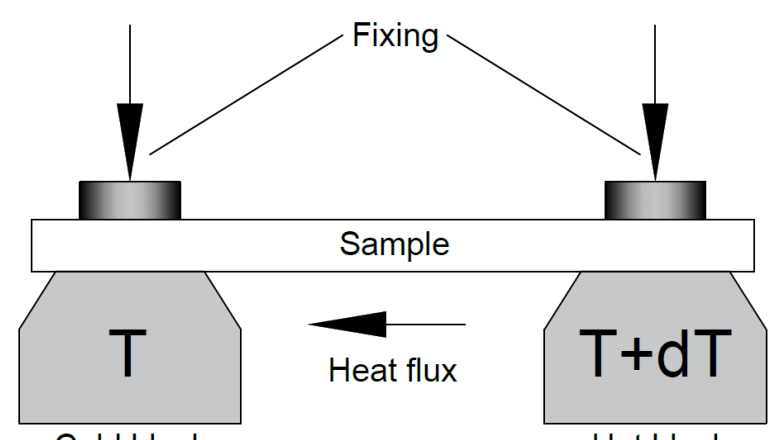

Cold block

Hot block

Figure 11. Sematic illustration of the TEP instrument.

The set-up contains two copper blocks, one of them is heated electrically, while the other is cooled by circulated water. The measuring temperatures can be controlled quickly and exactly due to the thermocouples which are built in the cold and the hot blocks. The thickness of the samples was $3.4 \mathrm{~mm}$. The contact surface of the samples were grinded with fine grinding paper (P1200) and then were cleaned with alcohol. Samples were put on the cold and hot blocks and were fixed with two isolated screws. Temperature of the cold block was about $15^{\circ} \mathrm{C}$ until the hot block was about $25^{\circ} \mathrm{C}$. The result was read after about $90 \mathrm{~s}$, when the value of the TEP stabilized. The results of the TEP measurments are presented in Figures 12 and 13.

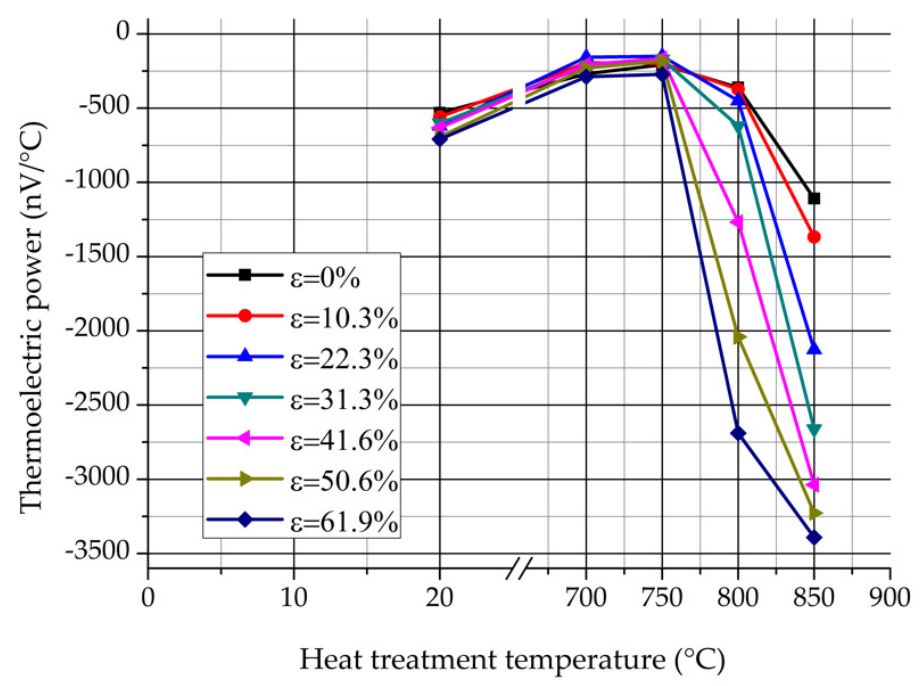

Figure 12. Values of the TEP in function of the heat treatment temperature.

Figure 12 shows the values of the TEP in function of the heat treatment temperature. It can be seen the values of the TEP are nearly independent of the deformation rate below $750{ }^{\circ} \mathrm{C}$. However, the previous cold rolling has an intensive effect on the TEP above $750{ }^{\circ} \mathrm{C}$. The stronger the plastic deformation rate, the lower the values of the TEP. The changing of the TEP above $750{ }^{\circ} \mathrm{C}$ is quite similar to the changing of the $\delta$-ferrite content, which were represented in Figures 6 and 8. 


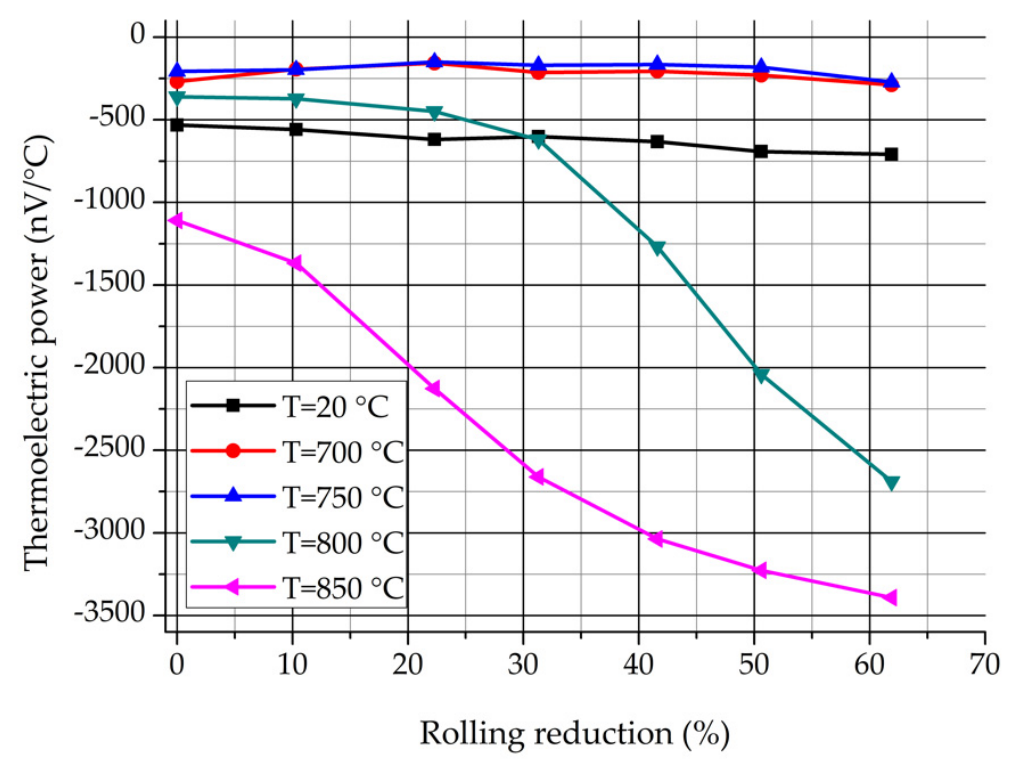

Figure 13. Values of the TEP in function of the rolling reduction.

Figure 13 shows the values of the TEP in function of the rolling reduction. It is known that the TEP is sensitive to the precipitations. The progressive decrease of the TEP at 800 and $850{ }^{\circ} \mathrm{C}$ can occur due to the precipitation of the significant amount of $\sigma$-phase, which forms during the eutectoidal decomposition. It can be seen that the values of the TEP are nearly independent of the deformation rate at 700 and $750{ }^{\circ} \mathrm{C}$, but higher than the values of the non-heat-treated samples. It is considered that the increase of the TEP is caused by those precipitations which appear previously to the $\sigma$-phase (e.g., $\mathrm{Cr}_{2} \mathrm{~N}, \mathrm{M}_{23} \mathrm{C}_{6}$, or $\chi$-phase) [3]. Based on the above, there is a good correlation between the process of the eutectoidal decomposition and the results of the TEP measurement.

\subsubsection{Foerster-Type DC Coercimeter Measurement}

The accurate value of the coercive field was measured by a Foerster DC coercimeter (Institut Dr. Förster, Reutlingen 1.094 and 1.106, Reutlingen, Germany) which is an open magnetization circuit equipment. Figure 14 shows the set-up of the DC coercimeter. The equipment contains a solenoid coil and two high-sensitivity magnetic field sensors, which are exactly in the middle outside of the coil.

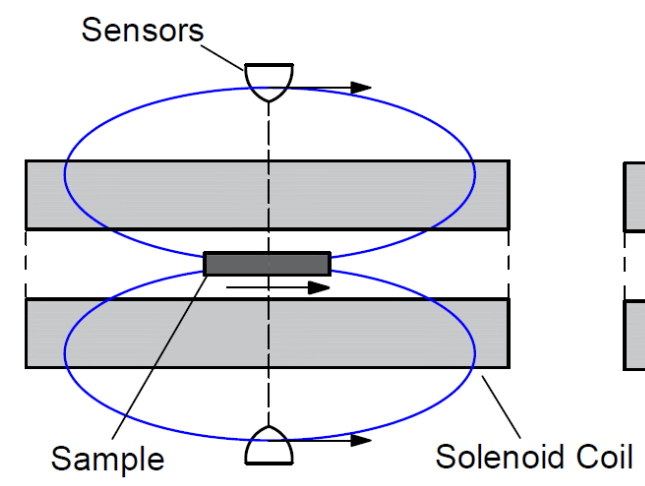

(a)

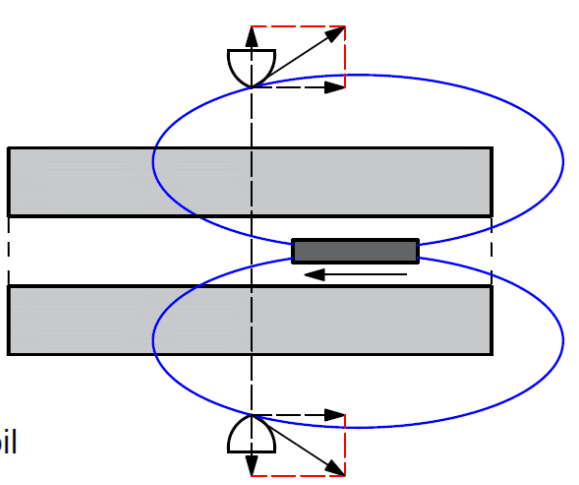

(b)

Figure 14. Set-up of the Foerster-type DC coercimeter: (a) First step of the measuring; (b) second step of the measuring.

As a first step (Figure 14a), the sample is put inside in the middle of the solenoid coil and magnetized into saturation. The polarization of the sample is measured by two sensors, which can 
measure the component of the magnetic field vector which is perpendicular to the coil. The sample creates a magnetic field outside the coil which is proportional with the magnetization of the sample. This magnetic field vector has just a horizontal component at the position of the sensors. As a second step (Figure 14b), the sample is moved horizontally in the solenoid coil until the sensors detect the maximal perpendicular component of the magnetic field vector. A reverse magnetic field is built up with the coil and it is increased until the measured perpendicular field component becomes zero. The reverse magnetic field is equal with the coercive field of the sample. The maximum of the magnetization field was $1000 \mathrm{~A} / \mathrm{cm}$.

Figure 15 represents the values of the coercive field in function of the heat treatment temperature. It can be noticed that the coercive field increases progressively in function of the heat treatment temperature by every rolling reduction. The increase is caused by two reasons: the plastic deformation and the appearance of the $\sigma$-phase. The coercive field of the non-heat-treated samples rises due to the cold rolling. $\sigma$-phase precipitations cause the increment of the coercive field by the undeformed samples. The increase of the coercive field is much higher by the strongly cold rolled samples than it is by the lower-extent deformed samples. The coercive field measurement showed the effect of the plastic deformation and the appearance of the $\sigma$-phase is not simply added by the cold rolled and heat treated samples, but the deformation stored energy increases the number of the $\sigma$-phase nuclei. It is considered that the reason for the coercive field increment is that the $\sigma$-phase precipitations prohibit the movement of the domain walls. The highly deformed samples ( $\varepsilon=41.6 \%, 50.6 \%$, and $61.9 \%$ ) after heat treatment at $850{ }^{\circ} \mathrm{C}$ became nearly paramagnetic. Their coercive field cannot be determined.

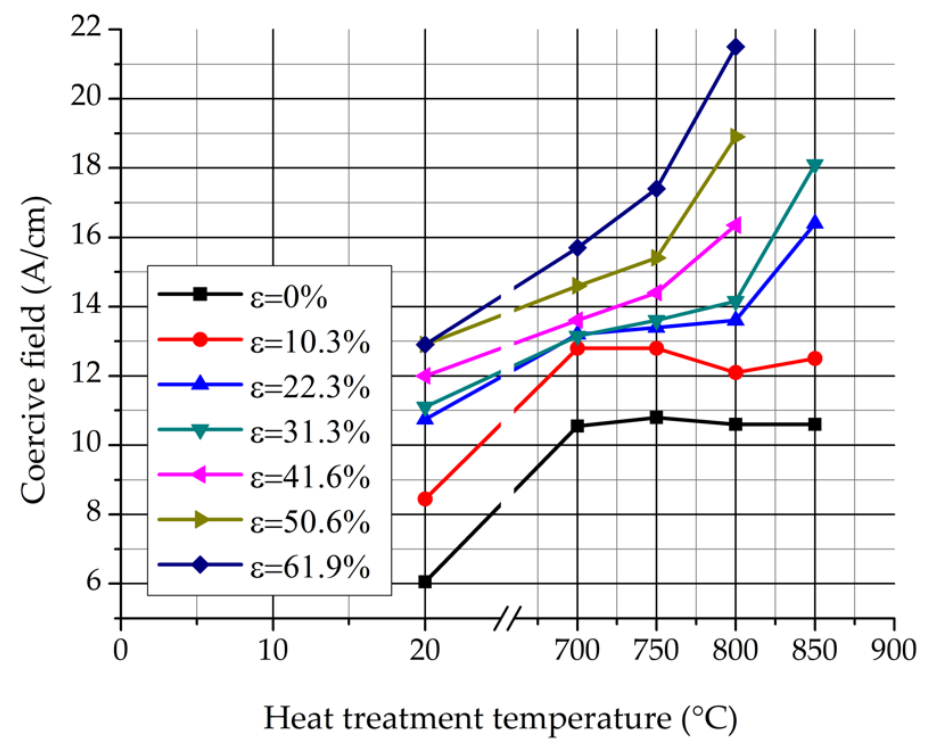

Figure 15. Values of the coercive field in function of the heat treatment temperature.

\subsubsection{Hardness Measurement}

The Vickers hardness (HV 10) of the samples were measured by a KB 250 BVRZ-type universal hardness testing machine, which was produced by KB Prüftechnik GmbH (Hochdorf-Assenheim, Germany). The measuring limit of the machine is $250 \mathrm{~kg}$ and the test room height is $320 \mathrm{~mm}$.

Figure 16 shows the hardness of the samples in function of the heat treatment temperature. The load was nominally $98.07 \mathrm{~N}$ during $12 \mathrm{~s}$. 


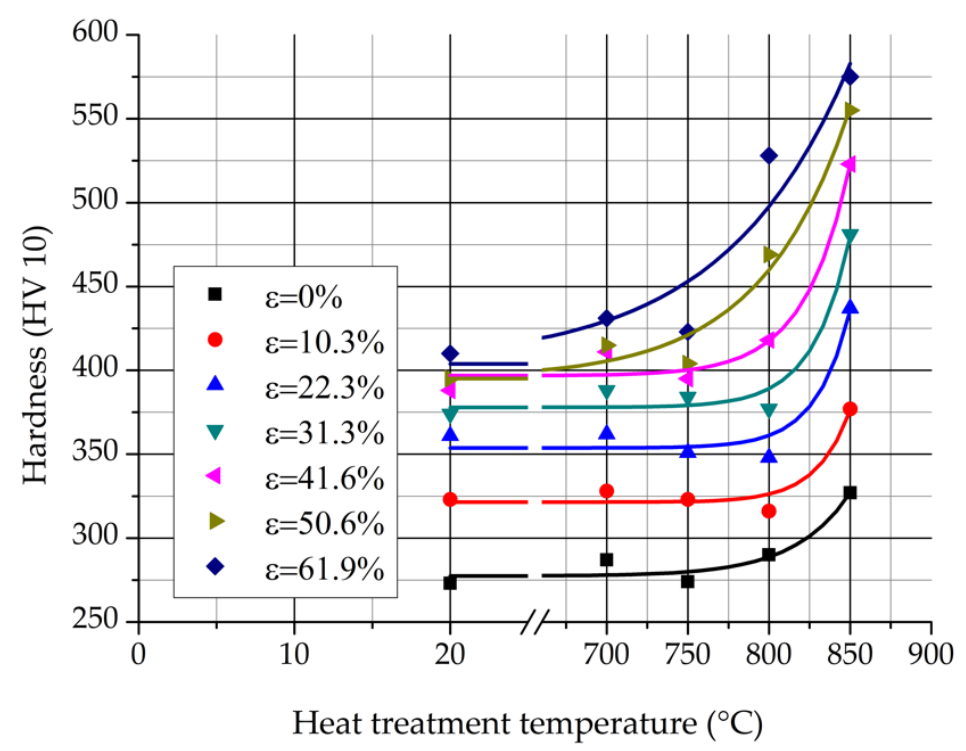

Figure 16. Hardness of the samples in function of the heat treatment temperature.

The hardness increase of the undeformed samples is $54 \mathrm{HV}$ until this rise of the strongly rolled samples is three times higher $(\varepsilon=50.6 \%$ and $61.9 \%)$. The increase of the hardness is caused by the dislocation hardening and the $\sigma$-phase precipitation, as it was specified in the before chapter. The previous cold rolling before the heat treatment increases the chance of nucleation of the $\sigma$-phase along the slip lines. More $\sigma$-phases can cause a higher increase in hardness.

\subsection{Second Sample Set}

The second sample set was prepared to determine the activation energy of the eutectoidal decomposition process. The samples were cold rolled and heat treated at $850{ }^{\circ} \mathrm{C}$ during different terms. The extents of the rolling reduction were similar to the first sample set: $\varepsilon=0 \%, 10.2 \%, 21.9 \%, 29.9 \%$, $40.9 \%, 50.1 \%$, and $61.1 \%$. The rolled samples were cut into eight smaller pieces and each piece was heat treated separately until the following terms: $t=0,20,25,30,35,40,45$, and $50 \mathrm{~min}$. The heat treated samples were normalized using static normal air.

Activation energy was calculated using the Avrami and Arrhenius equations. The activation energy can be considered as the minimal energy which is necessary for the beginning of a reaction or a phase transformation. This energy can describe a phase transformation numerically.

Kinetics equations are used to determine the time of a phase transformation in alloys, of which the most current is the Avrami equation. This equation gives a relationship between the transformed fraction and the time. Equation (4) shows the general form of the Avrami equation:

$$
y=1-\mathrm{e}^{-r t^{n}}
$$

where " $y$ " is the transformed fraction, " $t$ " is the time, and " $n$ " and " $r$ " are the variables. The exponential connection between the rate of the chemical reaction and the temperature is given by the Arrhenius equation which is showed with Equation (5):

$$
k=A e^{-\frac{E_{a}}{R T}}
$$

where " $k$ " is the rate of transformation, " $A$ " is the pre-exponential factor, " $E_{a}$ " is the activation energy, " $R$ " is the universal gas constant, and " $T$ " is the absolute temperature. The Arrhenius equation is applied for the description of the temperature dependence of thermally-activated processes [31-33]. 
Figure 17 shows the Avrami curves which were determined from the decomposed $\delta$-ferrite content. The curves were fitted by two parameters regression using the Avrami Equation (4) and the OriginPro 8 software (OriginLab, Northampton, MA, USA).

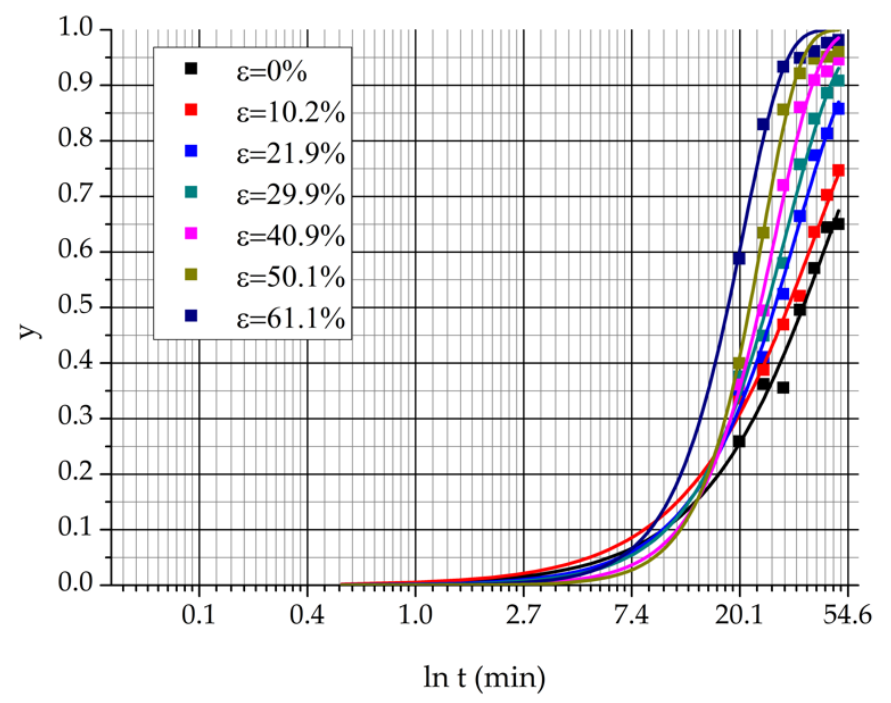

Figure 17. Avrami curves.

The rate of the transformation can be determined with the Avrami curves using Equation (6):

$$
k=\frac{1}{t_{0.5}}
$$

where $t_{0.5}$ is the time which belongs to the $y=0.5$ transformed fraction. Taking the logarithm of Equation (5), the activation energy can be calculated as Equation (7):

$$
E=R T(\ln A-\ln k)
$$

Value of the $\ln A$ was determined by the so-called Arrhenius plot using the data of the $61.9 \%$ deformed samples of the first sample set. It was supposed that its value is independent of deformation extent. The rate of transformation $(k)$ can be calculated from the amount of decomposed $\delta$-ferrite as Equation (8) shows:

$$
k=\left(F_{0} \%-F \%\right),
$$

where " $F_{0} \%$ " is the original $\delta$-ferrite content $(46.9 \%)$ and " $F \%$ " is the calculated $\delta$-ferrite content after the decomposition. Equation (9) shows the replacement of the " $k$ " in the natural logarithm of the Arrhenius equation:

$$
\ln \left(F_{0} \%-F \%\right)=\ln A-\frac{E_{a}}{R} \frac{1}{T}
$$

If "ln $\left(F_{0} \%-F \%\right)$ " is plotted in function of the " $1 / T$," the intercept of the line is equal with the value of the $\ln A$. Figure 18 shows the Arrhenius plot of the $\varepsilon=61.9 \%$ deformed first sample set. The obtained value of $\ln A$ was 28.82, which was substituted into Equation (7) for calculating the activation energy (E) values of the second sample set. 


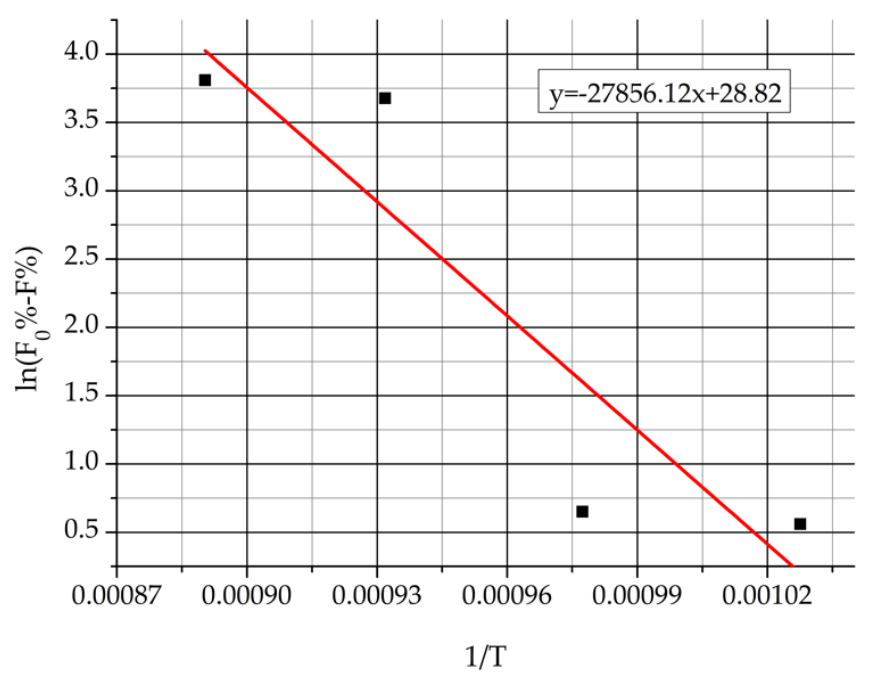

Figure 18. Arrhenius plot of the $\varepsilon=61.9 \%$ deformed original sample series.

Figure 19 represents the obtained activation energy values of the second sample set in function of the rolling reduction.

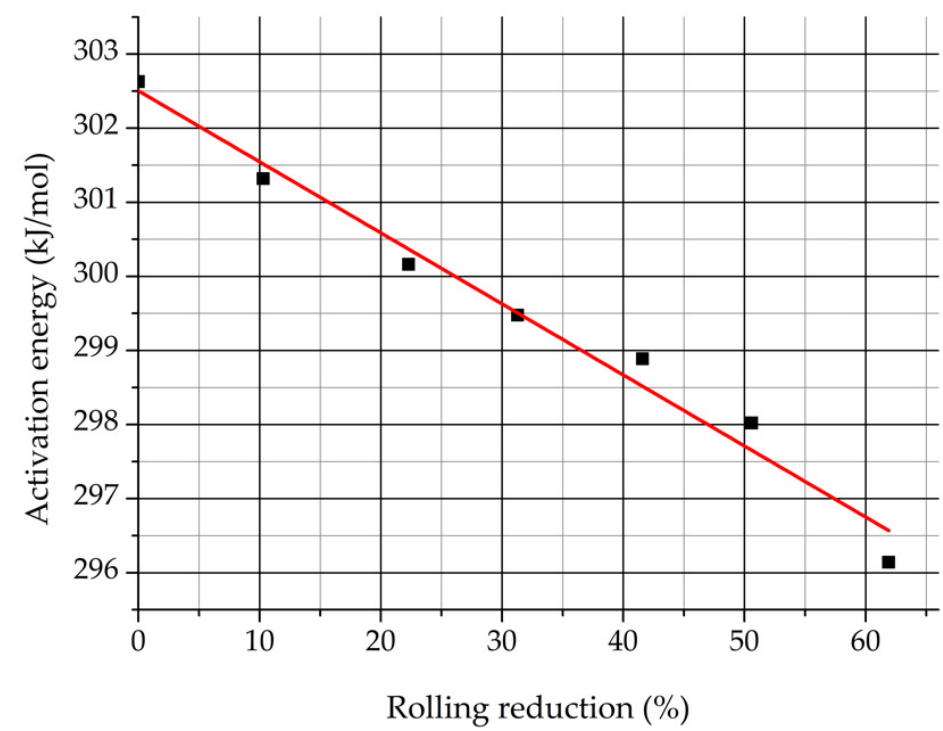

Figure 19. Activation energy in function of the rolling reduction.

It can be seen that the activation energy decreases from 302 to $296 \mathrm{~kJ} / \mathrm{mol}$ in function of the rolling reduction.

It is supposed that the rate limiting process of the $\delta$-ferrite decomposition is the diffusion of $\mathrm{Cr}$ and Mo in $\delta$-ferrite according to the kinetics described before. Slightly different activation energy values of $\mathrm{Cr}$ and Mo diffusion in ferrite are published in scientific papers. The typical values are $267.4 \mathrm{~kJ} / \mathrm{mol}(\mathrm{Cr}$ in ferrite) and $282.6 \mathrm{~kJ} / \mathrm{mol}$ (Mo in ferrite) [34-36], which are in good agreement with the obtained data.

It should be noticed that the determination of the activation energy with the Arrhenius fitting and Avrami equation is a very sensitive calculation method. If the $\delta$-ferrite content changed $3 \%$ by the Arrhenius fitting the calculated activation energy increased almost $30 \%$. The more accurate determination of the activation energy would require numerous samples. 


\subsection{Third Sample Set}

The third sample set was prepared to study how the eutectoidal phase transformation is influenced by plastic deformation technology that is different from cold rolling. Samples were elongated by single-axis tensile stress and were heat treated at $850^{\circ} \mathrm{C}$. The samples were in the furnace for $30 \mathrm{~min}$ and were normalized using static normal air. The effect of the cold rolling and the elongation for the eutectoidal phase transformation were compared.

The elongation was made by a Heckert EU-40-type hydraulic tensile test machine (Mönchengladbac, Germany), which measuring limit is $400 \mathrm{kN}$. The machine has a digital data acquisition card and its stroke length is about $600 \mathrm{~mm}$. The $\delta$-ferrite contents of the cold rolled samples and the elongated samples were compared based on the equivalent deformation. Measuring lengths were used to divide the elongated sample to equal volumes before the elongation. This division was necessary for the calculation of the equivalent deformation. Figure 20 illustrates the used volume division.

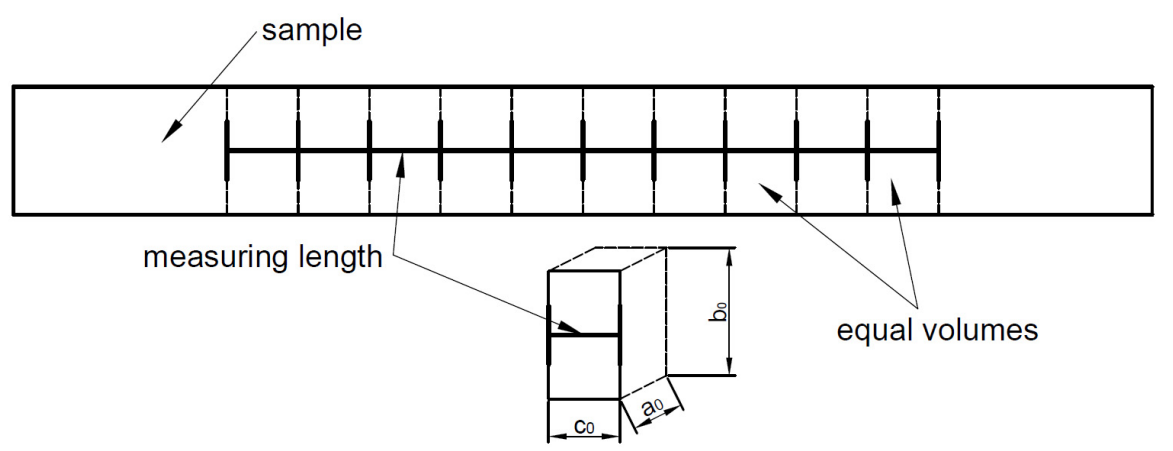

Figure 20. Volume division of the sample before the elongation.

The equivalent deformation of one part can be calculated using Equations (10)-(13) [37,38]:

$$
\begin{aligned}
& \bar{\varphi}=\frac{\sqrt{2}}{3} \sqrt{\left(\varphi_{x}-\varphi_{y}\right)^{2}+\left(\varphi_{x}-\varphi_{z}\right)^{2}+\left(\varphi_{y}-\varphi_{z}\right)^{2}} \\
& \varphi_{x}=\ln \frac{a}{a_{0}} \\
& \varphi_{y}=\ln \frac{b}{b_{0}} \\
& \varphi_{z}=\ln \frac{c}{c_{0}}
\end{aligned}
$$

where " $a_{0}$, " " $b_{0}$ ", and " $c_{0}$ " are the original sizes of one part; " $a$ ", " $b$ ", and " $c$ " are the deformed sizes of one part measured after the elongation. The equivalent deformation of the cold rolled samples can be calculated similarly by Equation (10). After the heat treatment, the $\delta$-ferrite content of the cold rolled samples and the elongated samples were measured. Figure 21 represent the $\delta$-ferrite contents in function of the equivalent deformation by the two different plastic deformation technologies. 


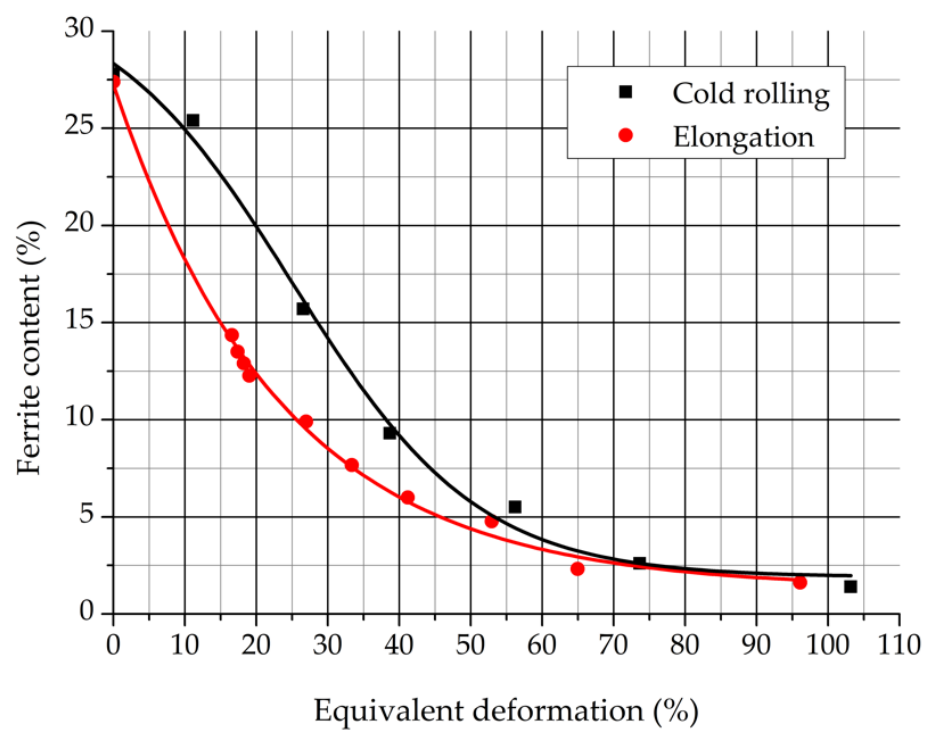

Figure 21. The equivalent deformation in function of the $\delta$-ferrite content.

It can be seen that the $\delta$-ferrite content reduction of the elongated samples is very similar to the results of the cold rolled samples. The stronger the previous deformation extent, the higher the amount of the decomposed $\delta$-ferrite. The single-axis tensile stress can influence the eutectoidal phase transformation process similarly to that of the stress state that forms during the cold rolling.

\section{Summary and Conclusions}

The eutectoidal phase transformation of 2507-type SDSS was examined in this complex study. The effect of the previous cold working and heat treatment was studied. Samples were differently cold worked and heat treated in three sets.

The first sample set was cold rolled at seven different rolling reductions up to $61.9 \%$, which was followed by heat treatment at five different temperatures up to $850^{\circ} \mathrm{C}$.

The second sample set was prepared to determine the activation energy of the eutectoidal decomposition. These samples were cold rolled at seven different rolling reductions and were heat treated at $850^{\circ} \mathrm{C}$ during eight different terms.

The third sample set was elongated by single-axis tensile stress and were heat treated at $850{ }^{\circ} \mathrm{C}$.

The $\delta$-ferrite contents were calculated using the results of $A C$ and DC magnetometer measurements. Because the coercivity of the studied SDSS samples was relatively high, the AC magnetometer was not able to saturate them magnetically. Therefore, the DC magnetometer was used in the following part of this work for determining the $\delta$-ferrite content. The accurate value of the coercive field was determined by a DC coercimeter device. Light microscope and EBSD images clearly demonstrated the process of the eutectoidal decomposition. The thermoelectric power and the hardness of the samples were also measured.

The results of all these measurements demonstrated the decomposition of the $\delta$-ferrite into $\sigma$-phase and secondary austenite with the same tendency. It was clearly demonstrated that previous cold rolling before heat treatment significantly increases the rate of eutectoidal decomposition and decreases its starting temperature.

It was demonstrated that the thermoelectric power measurement (TEP) is sensitive to the decomposition of $\delta$-ferrite phase. The TEP measurement is definitely a useful method for detecting the $\delta$-ferrite decomposition process.

The results of the magnetic measurements were compared with the results of TEP tests. It was concluded that up to $750^{\circ} \mathrm{C}$ there is no significant $\delta$-ferrite decomposition. Under $750{ }^{\circ} \mathrm{C}$ the previous cold working has no effect on the eutectoidal phase transformation. $\delta$-ferrite decomposition was 
detected at 800 and $850{ }^{\circ} \mathrm{C}$, whereby the previous plastic deformation strongly increased the rate of phase transformation.

The activation energy of the $\delta$-ferrite decomposition process was determined from the data of the second sample set. The obtained activation energy for the undeformed sample was $302 \mathrm{~kJ} / \mathrm{mol}$, and its value decreased due to previous cold rolling to $296 \mathrm{~kJ} / \mathrm{mol}$. These values are close to the activation energy values of the diffusion process of chromium and molybdenum in ferrite. Therefore, it can be concluded that the rate-limiting step of the whole diffusion-controlled phase transformation of $\delta$-ferrite is the diffusion of the two mentioned alloying elements.

The equivalent deformation rates of the cold rolled and single-axis elongated sample sets were compared. It was demonstrated that elongation had a stronger effect on the $\delta$-ferrite decomposition process in the $0 \%-70 \%$ equivalent deformation range than the cold rolling. Above $70 \%$ deformation, the two ways of plastic deformation had the same effect on the $\delta$-ferrite decomposition process.

Author Contributions: Conceptualization, I.M. and B.B.; methodology, I.M.; software, B.B.; validation, I.M.; investigation, B.B.; writing—original draft preparation, B.B.; writing—review and editing, I.M.; supervision, I.M.

Funding: The research reported in this paper was supported by the Higher Education Excellence Program of the Ministry of Human Capacities in the frame of nanotechnology research area of Budapest University of Technology and Economics (BME FIKP-NAT).

Conflicts of Interest: The authors declare no conflicts of interest.

\section{References}

1. Gunn, R.N. Duplex Stainless Steels, 1st ed.; Abington Publishing: Cambridge, UK, 1997; ISBN 1-85573-318-8.

2. Charles, J. Duplex stainless steels. Steel Res. Int. 2008, 79, 455-465. [CrossRef]

3. Bödök, K. Az Ötvözetlen, Gyengén és Erősen Ötvözött Szerkezeti Acélok Korrózióállósága, Különös Tekintettel Azok Hegeszthetőségére, 1st ed.; CorWeld: Budapest, Hungary, 1997; pp. 225-254, ISBN 963-04-8345-9.

4. Berecz, T.; Szabó, P.J. Crystallographic relations during decomposition of the ferritic phase by isothermal ageing in duplex stainless steel. J. Appl. Crystallogr. 2013, 46, 135-141. [CrossRef]

5. Berecz, T.; Szabó, P.J. Study of the isothermal phase transformations in duplex stainless steels by EBSD method. Mater. Sci. Forum 2005, 473, 177-182. [CrossRef]

6. Dyja, D.; Stradomski, Z.; Kolan, C.; Stradomski, G. Eutectoid decomposition of $\delta$-ferrite in ferritic-austenitic duplex cast steel-structural and morphological study. Mater. Sci. Forum 2012, 706, 2314-2319. [CrossRef]

7. Martins, M.; Casteletti, L.C. Sigma phase morphologies in cast and aged super duplex stainless steel. Mater. Charact. 2009, 60, 792-795. [CrossRef]

8. Stradomski, Z.; Dyja, D. Sigma Phase Precipitation in Duplex Phase Stainless Steels. Available online: www.researchgate.net/publication/266054376_SIGMA_PHASE_PRECIPITATION_IN_DUPLEX_ PHASE_STAINLESS_STEELS (accessed on 8 July 2019).

9. Guocai, C.; Pasi, K. Super and hyper duplex stainless steels: Structures, properties and applications. Procedia Struct. Integr. 2016, 2, 1755-1762. [CrossRef]

10. Llorca-Isern, N.; López-Luque, H.; López-Jiménez, I.; Biezma, V.M. Identification of sigma and chi phases in duplex stainless steels. Mater. Charact. 2016, 112, 20-29. [CrossRef]

11. Sieurin, H.; Sandström, R. Sigma phase precipitation in duplex stainless steel 2205. Mater. Sci. Eng. A 2007, 444, 271-276.

12. Breda, M.; Brunelli, K.; Grazzi, F.; Scherillo, A.; Calliari, I. Effects of cold rolling and strain-induced martensite formation in a SAF 2205 duplex stainless steel. Metall. Mater. Trans. A 2015, 46, 577-586. [CrossRef]

13. Calliari, I.; Bassani, P.; Brunelli, K.; Breda, M.; Ramous, E. Effect of continuous cooling on secondary phase precipitation in the super duplex stainless steel Zeron-100. J. Mater. Eng. Perform. 2013, 22, 3860-3866. [CrossRef]

14. Nilsson, J.O. Super duplex stainless steels. Mater. Sci. Technol. 1992, 8, 685-700. [CrossRef]

15. Hättestrand, M.; Larsson, P.; Chai, G.; Nilsson, J.O.; Odqvist, J. Study of decomposition of ferrite in duplex stainless steel cold worked and aged at $450-500{ }^{\circ}$ C. Mater. Sci. Eng. A 2009, 499, 489-492. [CrossRef]

16. Nenno, S.; Tagaya, M.; Hosomi, K.; Nishiyama, Z. Electron microscope study of sigma phase precipitation in an iron-chromium-nickel alloy. Trans. JIM 1963, 4, 222-231. [CrossRef] 
17. Hall, E.O.; Algie, S.H. The sigma phase. Int. Mater. Rev. 1966, 11, 61-88. [CrossRef]

18. Ramirez, A.J.; Lippold, J.C.; Brandi, S.D. The relationship between chromium nitride and secondary austenite precipitation in duplex stainless steel. Metall. Mater. Trans. A 2003, 34, 1575-1597. [CrossRef]

19. Fiorillo, F. Measurement and Characterization of Magnetic Materials, 1st ed.; Elsevier: Amsterdam, The Netherlands, 2004; ISBN -13 978-0-12-257251-7.

20. Takacs, J.; Mészáros, I. Separation of magnetic phases in alloys. Phys. B 2008, 403, 3137-3140. [CrossRef]

21. Cullity, B.D.; Graham, C.D. Introduction to Magnetic Materials, 2nd ed.; Wiley-IEEE Press: Hoboken, NJ, USA, 2009; ISBN 978-0-471-47741-9.

22. Stablein, F.; Steinitz, R. Ein Neuer Doppeljoch-Magnetstalprufer. Arch. Fur Das Eisenhuttenwes. 1935, 8, 549-554. [CrossRef]

23. Meszaros, I. Testing of Stainless Steel BY double yoke DC magnetometer. J. Electr. Eng. 2010, 61, 62-65.

24. Bozorth, R.M. Ferromagnetism; Wiley-IEEE Press: Hoboken, NJ, USA, 1993; ISBN 978-0-7803-1032-2.

25. Mitra, S. Sample Preparation Techniques in Analytical Chemistry; John Wiley \& Sons, Inc.: Hoboken, NJ, USA, 2003; Volume 162.

26. Dobránszky, J.; Szabó, P.J.; Berecz, T.; Hrotkó, V.; Portkó, M. Energy dispersive spectroscopy and electron backscatter diffraction analysis of isothermally aged SAF 2507 type superduplex stainless steel. Spectrochim. Acta Part B At. Spectrosc. 2004, 59, 1781-1788. [CrossRef]

27. Choi, S.H.; Jin, Y.S. Evaluation of stored energy in cold-rolled steels from EBSD data. Mater. Sci. Eng. A 2004, 371, 149-159. [CrossRef]

28. Lara, N.O.; Ruiz, A.; Rubio, C.; Ambriz, R.R.; Medina, A. Nondestructive assessing of the aging effects in 2205 duplex stainless steel using thermoelectric power. NDT \& E Int. 2011, 44, 463-468. [CrossRef]

29. Kléber, X.; Dobránszky, J.; Alain, V. A termoelektromos erő mérés alkalmazása a fémtani folyamatok vizsgálatában. Anyagvizsgálók Lapja 2001, 11, 6-9.

30. Houzé, M.; Kleber, X.; Fouquet, F.; Delnondedieu, M. Study of molybdenum precipitation in steels using thermoelectric power measurement. Scr. Mater. 2004, 51, 1171-1176. [CrossRef]

31. Magnabosco, R. Kinetics of sigma phase formation in a duplex stainless steel. Mater. Res. 2009, 12, 321-327. [CrossRef]

32. Kang, M.; Zhang, M.X.; Liu, F.; Zhu, M. Kinetics and morphology of isothermal transformations at intermediate temperature in 15CrMnMoV steel. Mater. Trans. 2009, 50, 123-129. [CrossRef]

33. Laidler, K.J. The development of the Arrhenius equation. J. Chem. Educ. 1984, 61, 494-498. [CrossRef]

34. Wang, Z.B.; Tao, N.R.; Tong, W.P.; Lu, L.; Lu, K. Diffusion of chromium in nanocrystalline iron produced by means of surface mechanical attrition treatment. Acta Mater. 2003, 51, 4319-4329. [CrossRef]

35. Nitta, H.; Yamamoto, T.; Kanno, R.; Takasawa, K.; Iida, T.; Yamazaki, Y.; Ogu, S.; Iijima, Y. Diffusion of molybdenum in $\alpha$-iron. Acta Mater. 2002, 50, 4117-4125. [CrossRef]

36. Błachowski, A.; Dubiel, S.M.; Żukrowski, J. On the activation energy of the $\sigma$-phase formation in a pure and Ti-doped Fe-Cr alloy. Intermetallics 2001, 9, 493-498. [CrossRef]

37. Chen, W.F.; Han, D.J. Plasticity for Structural Engineers; Springer: New York, NY, USA, 1988; ISBN 0387967117.

38. Jones, R.M. Deformation Theory of Plasticity; Bull Ridge Publishing: Blacksburg, VA, USA, 2009; ISBN 978-0-9787223-1-9.

(C) 2019 by the authors. Licensee MDPI, Basel, Switzerland. This article is an open access article distributed under the terms and conditions of the Creative Commons Attribution (CC BY) license (http://creativecommons.org/licenses/by/4.0/). 